\title{
THE BELFAST ATOMIC DATA BANK, RECOMMENDED DATA, AND THE OPACITY PROJECT DATA BASE
}

\author{
K.A. BERRINGTON, A.E. KINGSTON and P.M.J. SAWEY \\ Department of Applied Mathematics and Theoretical Physics, The Queen's \\ University of Belfast, GB-Belfast, BT7 1NN, Great-Britain
}

\begin{abstract}
Résumé
La Belfast Atomic Data Bank contient des données sur l'excitation et 1 'ionisation des atomes et des ions par des électrons et des photons, et fournit des données recommandées; les données recommandées lors d'Atomic Data Workshops réguliers pour 1'excitation électronique sont résumées. Des données sur la photoabsorption pour tous les éléments jusqu'à $\mathrm{Fe}$ ont été calculées dans le cadre du projet international Opacity, et un résumé est fait des données atomiques attendues du Projet.
\end{abstract}

\section{$\underline{\text { Abstract }}$}

The Belfast Atomic Data Bank holds data for the excitation and ionisation of atoms and ions by electrons and photons, and provides recommended data; electron excitation data recommended at regular Atomic Data Workshops is summarised. Photoabsorption data for all elements up to Fe have been calculated in the international Opacity Project, and a summary is given of the atomic data expected from the Project.

\section{1 - THE BELFAST ATOMIC DATA BANK AND RECOMMENDED DATA}

The efficient application of atomic data, for example to plasma modelling or diagnostics, requires the data in computer-readable form. In any case, journal space usually limits the amount of data that can be published, and there is a danger that detailed but bulky collision data, so painstakingly calculated in a particular piece of research, may be lost to the user community afterwards. Thus there is a need for computer-based data banks to hold these data.

The Belfast Atomic Data Bank /1/ provides a system for the storage, manipulation and dissemination of atomic data. The processes considered are the excitation and ionisation of atoms and ions by electrons and photons. The Data Bank contains the largest collection of electron-atom and ion collision data in the world, and contains data from the most elaborate calculations available, for example from R-matrix calculations.

The Data Bank also produces recommended electron impact excitation and ionisation /2,3/ rates for the applications community, and is involved in the Atomic Data Workshops described below. 
International Atomic Data Workshops are held regularly to evaluate all calculated atomic data for particular processes, such as electron excitation and photoionisation. The first meeting was held at Los Alamos in $1980 / 4 /$; more recently meetings have been held at: the S.E.R.C Daresbury Laboratory, 29-31 March 1985 /5,6/; St Catherine's College Oxford, 1-2 August 1987/7/; and the Observatoire de Mendon, 4-6 September 1989 /8/.

Electron excitation data recommended in the Atomic Data Workshops are held in the Belfast Atomic Data Bank in the form of thermally-averaged effective collision strengths or rate coefficients. The data are stored in ASCII files, one file for each ion. An illustrative example is shown in table 1. Apart from headers giving the reference and transition information, the data basically consists of three columns: the electron temperature, rate coefficient and effective collision strength. Table 2 summarises the atoms and ions for which electron excitation data has been recommended at the Workshops. These data can be obtained from the Belfast Atomic Data Bank by contacting the author of this paper, or by electronic mail to the JANET address: DATABANK @ UK.AC.QUB.AMV1.

\section{2 - ATOMIC DATA FOR OPACITY CALCULATIONS}

The aim of the Opacity Project, as outlined by Seaton $/ 9 /$, is to calculate $a b$ initio a complete set of atomic photoabsorption data using state-of-the-art computational techniques, and to interface these data with methods for nonlinear radiation hydrodynamics involving the solution of a realistic equation-of-state, to produce accurate raciative opacities for stellar envelopes. The collaboration involves atomic physicists and astrophysicists in London, Belfast, Paris, Nice, Munich, Caracas, Boulder, Urbana and Ohio. The following gives the scope of the database:

* data for all ionisation stages of the astrophysically important elements from $\mathrm{H}$ to Fe: about one hundred atoms and ions;

* all LS terms for each ion up to $n=10$ and $l=3$ or 4 (a hydrogenic approximation being used for the rest): totalling hundreds of thousands of states;

* oscillator strengths between all these states connected by the dipole selection rules: tens of millions of transitions;

* photoionisation cross sections for all bound states at an energy grid sufficient to delineate the resonance structure: thousands of millions of cross section values;

* line profile parameters.

It is hoped that by the end of 1991 the complete set of atomic data will be published, and the entire Opacity Project data base will then be made available in computer-readable form. The Belfast Atomic Data Bank holds a copy of the data base, and copies exist also at JILA (D. G. Hummer), Ohio (A. K. Pradhan) and at Meudon (C. J. Zeippen).

\section{REFERENCES}

/1/ Hughes, J.G., Smith, F.J., Berrington, K.A., Aggarwal, K.M. and Elder, M., Comput. Phys. Commun. 33 (1984) 99.

/2/ Bell, K. L., Gilbody, H. B., Hughes, J. G., Kingston, A. E. and Smith, F. J., Atomic and molecular data for fusion, part 1. Recommended cross sections and rates for electron ionisation of light atoms and ions. UKAEA Report CLM-R216 (1982), Culham Laboratory, 
Abingdon, Oxfordshire, U. K.

/3/ Lennon, M. A., Bell, K. L., Gilbody, H. B., Hughes, J. G., Kingston, A. E., Murray, M. J. and Smith, F. J., Atomic and molecular data for fusion, part 2. Recommended cross sections and rates for electron ionisation of atoms and ions: fluorine to nickel. UKAEA Report CLM-R270 (1986), Culham Laboratory, Abingdon, Oxfordshire, U. K.

/4/ Merts, A. L., Mann, J. B., Robb, W. D. and Magee Jr., N. H. Los Alamos Scientific Laboratory Report No. LA-8267-MS (1980).

/5/ Atomic Data Workshop: Low energy collision theory techniques for atomic excitation and radiative data. Proceedings of the Daresbury study weekend 29-31 March 1985 (compiled by W. B. Eissner). Report DL/SCI/R24 (Theory). SERC Daresbury Laboratory, Daresbury, Warrington WA4 4AD, U. K.

/6/ Report on Recommended Data: Atomic Data Workshop, Daresbury, March 1985 (Eds. K. M. Aggarwal, K. A. Berrington W. Eissner and A. E. Kingston). SERC Daresbury Laboratory, Daresbury, Warrington WA4 4AD, U. K.

17/ Atomic Data Workshop: Assessment of data for photo-ionisation and photo-excitation and for electron impact excitation of atomic ions. Proceedings of the Workshop held at St Catherine's College Oxford 1-2 August 1987 (eds. W. Eissner and A. E. Kingston). SERC Daresbury Laboratory, Daresbury, Warrington WA4 4AD, U. K.

18/ Third Atomic Data Workshop Meudon, 4-6 September 1989. Proceedings to be published in Les editions de Physique.

/9/ Seaton, M. J., J. Phys. B: At. Mol. Phys. 20 (1987) 6363 ff.

Table 1. The Belfast Atomic Data Bank format for storage of the temperature dependent (column 1) electron excitation rate coefficients (column 2) and/or the effective collision strength (column 3), preceded by information on source, transition, etc. The example shown is for $\mathrm{e}^{-}-\mathrm{C}^{2+}, 2 s^{2}{ }^{1} \mathrm{~S}^{e}-2 \mathrm{~s} 2 \mathrm{p}^{3} \mathrm{p}$ ( (i.e. state 1 to state 2 ). Data are available in this format for all the ions in table 2 , for many transitions.

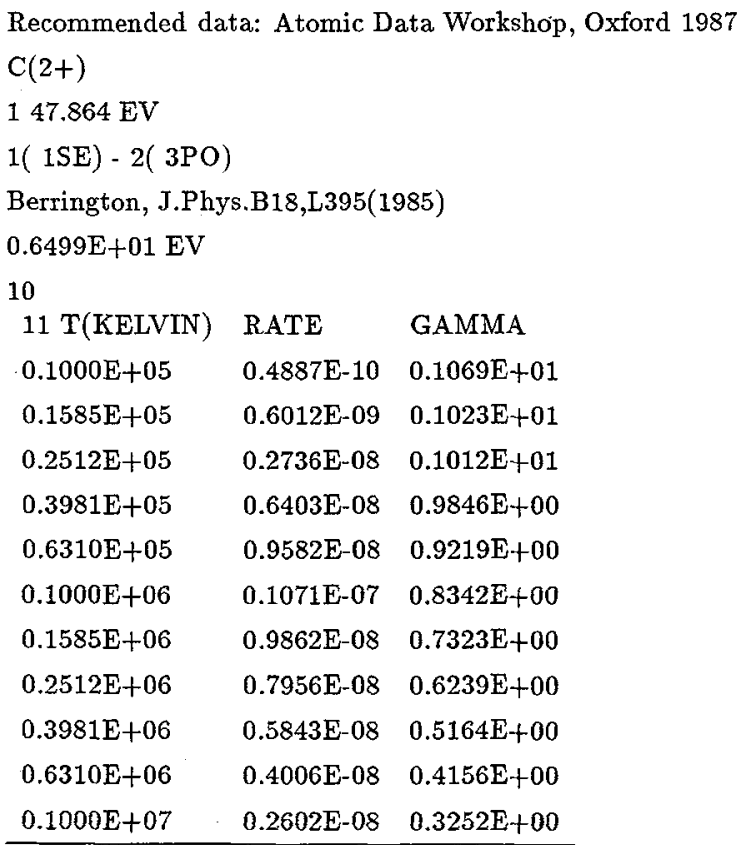


Table 2. Datasets of electron excitation rate coefficients for atoms and ions recommended in the Atomic Data Workshops /5,6,7/ and stored in the Belfast Atomic Data Bank. Note that the omission of a given ion in this list does not imply there are no data available; merely that no recommendations were made for that ion.

\begin{tabular}{|c|c|c|c|c|c|c|c|c|}
\hline \multicolumn{9}{|l|}{$\mathrm{HI}$} \\
\hline He I & $\mathrm{He} I I$ & & & & & & & \\
\hline Li III & & & & & & & & \\
\hline Be II & Be III & Be IV & & & & & & \\
\hline B V & & & & & & & & \\
\hline C I & C II & C III & C IV & $\mathrm{C} \mathrm{V}$ & C VI & & & \\
\hline N I & N II & $\mathrm{N} \mathrm{III}$ & $\mathrm{N} \mathrm{V}$ & N VII & & & & \\
\hline O I & O II & O III & O IV & $\mathrm{OV}$ & O VI & O VII & & \\
\hline F IX & & & & & & & & \\
\hline $\begin{array}{l}\mathrm{Ne} I I \\
\mathrm{Na} \mathrm{XI}\end{array}$ & $\mathrm{Ne} I I I$ & $\mathrm{Ne}$ IV & $\mathrm{Ne} \mathrm{V}$ & $\mathrm{Ne}$ VII & Ne VIII & $\mathrm{NeX}$ & & \\
\hline $\mathrm{Mg}$ VI & $\mathrm{Mg}$ VII & $\mathrm{Mg} X I$ & $\mathrm{Mg}$ XII & & & & & \\
\hline Al II & Al XIII & & & & & & & \\
\hline $\begin{array}{l}\text { Si II } \\
\text { P XV }\end{array}$ & Si III & Si VII & Si VIII & Si IX & $\operatorname{Si} X$ & Si XI & Si XII & Si XIV \\
\hline S II & S III & S IV & S V & S IX & S X & S XII & SXVI & \\
\hline Cl IV & $\mathrm{Cl}$ XVII & & & & & & & \\
\hline $\begin{array}{l}\mathrm{Ar} \mathrm{V} \\
\mathrm{K} \text { XIX }\end{array}$ & Ar XI & Ar XII & Ar XIII & Ar XV & Ar XVI & Ar XVIII & & \\
\hline Ca XIV & $\mathrm{Ca} X \mathrm{XV}$ & $\mathrm{Ca} X V I$ & $\mathrm{Ca}$ XVII & $\mathrm{Ca}$ XIX & $\mathrm{Ca} \mathrm{XX}$ & & & \\
\hline Sc XXI & & & & & & & & \\
\hline Ti XXII & & & & & & & & \\
\hline V XXIII & & & & & & & & \\
\hline Cr XXIV & & & & & & & & \\
\hline $\mathrm{Mn} X \mathrm{XV}$ & & & & & & & & \\
\hline $\begin{array}{l}\mathrm{Fe} \text { II } \\
\text { Se XXV }\end{array}$ & $\mathrm{Fe} X \mathrm{~V}$ & Fe XVIII & Fe XXIII & Fe XXIV & Fe XXV & Fe XXVI & & \\
\hline
\end{tabular}

